Article

\title{
Polymorphism of Interleukin 1B May Modulate the Risk of Ischemic Stroke in Polish Patients
}

\author{
Iwona Gorący ${ }^{1, *(D)}$, Mariusz Kaczmarczyk ${ }^{1}$, Andrzej Ciechanowicz ${ }^{1}$ (D), \\ Klaudyna Lewandowska ${ }^{1}$, Paweł Jakubiszyn ${ }^{1}$, Oksana Bodnar ${ }^{2}$, Bartosz Kopijek ${ }^{3}$, \\ Andrzej Brodkiewicz ${ }^{3}$ and Lech Cyryłowski ${ }^{4}$ \\ 1 Department of Clinical and Molecular Biochemistry, Pomeranian Medical University, 70-111 Szczecin, Poland \\ 2 Department of General and Dental Radiology, Pomeranian Medical University, 70-111 Szczecin, Poland \\ 3 Department of Pediatrics, Child Nephrology, Dialysotherapy and Management of Acute Poisoning, \\ Pomeranian Medical University, 71-899 Szczecin, Poland \\ 4 Department of Intervention Radiology, Pomeranian Medical University, 70-111 Szczecin, Poland \\ * Correspondence: igor@pum.edu.pl
}

Received: 22 July 2019; Accepted: 28 August 2019; Published: 2 September 2019

check for updates

\begin{abstract}
Background and Objectives: Inflammation plays a crucial role in the pathophysiology of ischemic stroke (IS). Interleukin-1B and interleukin-1 receptor antagonists are key factors in inflammatory processes. Aims: The aims of our study were to evaluate the relationship between genetic variation in interleukin-1B (IL1B) rs1143627 and interleukin-1 receptor antagonist (IL1RN) variable-number-tandem-repeats (VNTR), and overall IS and subtype prevalence rates. Materials and Methods: The analysis included 147 hospitalized Polish patients with IS diagnosed using conventional criteria. The control group consisted of 119 healthy subjects. Genotypes were determined by polymerase chain reaction. Results: A significant association between rs1143627 and stroke was found. The -31C IL1B polymorphism showed an association with overall IS, OR $=2.30(1.36-3.87) p=0.020$. An association was also detected for LVI (large vessel infarction) subtypes of stroke. After risk factor adjustment (age, diabetes mellitus, dyslipidemia), the $C$ allele was found to be an independent risk factor for LVI, OR $=1.99$ (1.05-3.79) $p=0.036$. Significant association was not observed between IL1RN alleles and IS. Conclusions: Our results suggest that the C allele of IL1B rs1143627 may be associated with susceptibility to overall IS and LVI subtypes of stroke in the Polish population.
\end{abstract}

Keywords: IL1B; IL1RN; polymorphism; stroke; inflammation

\section{Introduction}

Ischemic stroke (IS) is a multifactor disease, resulting from classical and genetic risk factors and their interactions. Accumulating evidence supports a critical role of inflammation in the pathogenesis of IS. Interleukin-1 (IL1) is one of the key pro-inflammatory cytokines which plays a key role in this inflammatory process. The IL1 family consists of IL1A, IL1B and one antagonist cytokine, the IL1 receptor antagonist (IL1RA) [1,2]. IL1A and IL1B are inflammatory factors produced by different cell types in response to various stimuli. They affect the endothelial cells, including the induction of adhesion molecules and prothrombotic effects, while the naturally occurring competitive IL1RA may antagonize the immune response. Disturbed balance in the action of IL1A, IL1B and IL1RA leads to the development and progression of atherosclerosis. In fact, earlier studies have shown that increased levels of inflammatory cytokines are associated with vascular ischemic disease [3-5].

The IL1 gene cluster, with loci on chromosome 2, encompasses the ILIA, IL1B, and ILIRN genes. The polymorphisms in this IL1 gene cluster, including IL1B and ILIRN (interleukin-1 receptor 
antagonist, encoding IL1RA), have been commonly studied and appeared to be associated with plasma levels of IL1B and ILRA [6,7].

In experimental studies, several independent groups have reported an early increase in IL1 expression in response to cerebral ischemia in rodents [8,9]. It has also been demonstrated in wild-type (WT) and knock-out IL1RI (IL1RI KO) mice that IL1 may exacerbate ischemic brain injury independently of IL1RI, which suggests the existence of an additional IL1 receptor or receptors in the brain [10]. Currently, IL1 polymorphism is considered to be an independent risk factor for IS development, although some studies have not confirmed this relationship.

The polymorphism in intron 2 of the interleukin receptor antagonist gene (IL1RN) is caused by the variable copy number of an 86-bp sequence. The most common allele, allele 1 (IL1RN $\left.{ }^{*} 1\right)$, contains two repeats. The alleles $2,3,4$, and 5 have two, five, three, and six repeats, respectively [11]. The IL1RN*2 allele of the variable number tandem repeat (VNTR) of IL1RN has been reported to be associated with increased ILRA production, which naturally downregulates the immune response [12]. However, some studies have shown that IL1RN*2 is associated with decreased IL1RA production. IL1B influences the endothelium, including the induction of adhesion molecules and procoagulant activity. Thus, the IL1/IL1RA balance may modulate inflammation processes which may contribute to the pathogenesis of ischemic stroke. A pro-inflammatory profile comprising SNPs in gene encoding regions of IL1B and ILIRN was further reported to confer an increased risk of atherosclerosis development [13-15] and some studies have reported that IL1B and IL1RN polymorphisms are associated with genetic risk of IS [16]. However, other studies on different populations did not confirm this and the association remains controversial $[17,18]$.

Ischemic stroke is a disease with devastating consequences, which is why we are still looking for markers enabling early diagnosis. Currently, many risk factors are known for the development of stroke. However, our knowledge concerning the genes which promote the development of stroke is still limited. Our study attempts to explain the role of the genetic variants of IL1B (C(-31)T)and IL1RN, considered to be key factors regulating inflammatory processes in the development of ischemic stroke. Therefore, we have investigated the possible association between genetic variation in IL1B rs 1143627 and ILIRN VNTR with overall IS and subtypes of IS classified by TOAST (see Materials and Methods) in the Polish population.

\section{Materials and Methods}

\subsection{The Study Group}

A total of 147 unrelated patients ( 80 males and 67 females) were admitted to hospital because of acute brain ischemic stroke (IS): Diagnosed using conventional criteria, including rapidly developed focal or global disturbance of cerebral function lasting more than $24 \mathrm{~h}$, without CT signs of a hemorrhagic lesion in the brain. The study group was from a homogeneous Polish population. All 147 patients underwent clinical scrutiny, investigation of medical history and family anamnesis, evaluation of vascular risk factors, general physical and neurological examinations, routine biochemical analyses, ECG (electrocardiography), and computed tomography (CT) of the brain, within two days of onset.

Data from risk factors were recorded, including arterial hypertension (HT, defined as systolic blood pressure exceeding $140 \mathrm{mmHg}$ or diastolic blood pressure greater than $90 \mathrm{mmHg}$ or previous diagnosis), body mass index (BMI, calculated as weight/height $\left.{ }^{2}\right)$, and diabetes (DM, previously diagnosed or a fasting plasma glucose concentration $>7.8 \mathrm{~mL} / \mathrm{L}$ ). Patients were classified as "current smokers" if they reported smoking more than five cigarettes per day. Routine biochemical analyses were done including fasting blood glucose, total cholesterol, HDL cholesterol and triglycerides, liver, and kidney function tests.

The study population was divided according to the TOAST classification [19], which identified five causes of ischemic cerebral infarction: (1) Large artery atherosclerosis (LVI-large-vessel infarction) in 71 patients $(46.7 \%)$, (2) small-vessel occlusion (SVI—small vessel infarction) in 40 patients $(26.3 \%)$, 
(3) cardioembolism (CEI-cardioembolic infarction) in 24 patients (15.8\%), (4) stroke of other determined etiology (e.g., non-atherosclerotic artery disease) in no patients, and (5) stroke of unknown etiology in 17 patients $(11.2 \%)$.

The control group consisted of 119 subjects (65 men, 52 women) who reported non-specific chest complaints and were diagnosed in regard to CAD. They underwent coronary angiography which detected no lesions in coronary arteries. A medical examination ruled out IS and other atherosclerotic diseases as well as a history of ischemic, hemorrhagic, and other brain diseases. The protocol of the study was approved by the Pomeranian Medical University Ethics Committee (nr BN-001/119/03/16.03.2003), with formal informed consent signed by all participants.

\subsection{Genotyping}

Genomic DNA was isolated from peripheral blood leukocytes using a commercial kit (QIAamp DNA Mini Kit; Qiagen, Hilden, Germany).

For the analysis of C(-31)T IL1B gene polymorphism (rs1143627) a polymerase chain reaction/restriction fragments length polymorphism (PCR/RFLP) method was applied with the following primer pair: Forward: 5' AgA AgC TTC CAC CAA TAC TC, and reverse: 5' AgC ACC TAg TTg TAA ggA Ag (TIB MOL BIOL, Poznań, Poland). Amplification was performed in volumes of $10 \mu \mathrm{L}$ containing $40 \mathrm{ng}$ genomic DNA, $0.1 \mu \mathrm{L}$ of each primer, $5 \mu \mathrm{L} 2$ xPCR Master Mix (Fermentas, Vilnius, Lithuania). The reactions were run under the following conditions: Denaturation $\left(94{ }^{\circ} \mathrm{C}\right.$, $5 \mathrm{~min}$ ), annealing $\left(56^{\circ} \mathrm{C}, 40 \mathrm{~s}\right)$, and extension $\left(72{ }^{\circ} \mathrm{C}, 8 \mathrm{~min}\right)$. Thirty-five cycles were performed using a Mastercycler gradient machine (Eppendorf, Hamburg, Germany). The resulting product (234 bp) was digested with the Alu I restriction enzyme (MBI Fermentas, Vilnius, Lithuania), and the digestion products were separated in $4 \%$ agarose gels. The polymorphic region within intron 2 of the IL1RN gene was amplified using polymerase chain reaction (PCR). Genomic DNA (20 ng) served as a template in the $10 \mu \mathrm{L}$ PCR reaction. This reaction contained the following components: $0.1 \mu \mathrm{L}$ of each forward primer: 5' CCC CTC AgC AAC ACT CC, and reverse primer: 5' ggT CAg AAg ggC AgA gA (TIB MOL BIOL, Berlin, Germany); $5 \mu \mathrm{L}$ 2xPCR Master Mix (Fermentas, Vilnius, Lithuania) the reaction was performed using standard settings: Denaturation $\left(94^{\circ} \mathrm{C}, 5 \mathrm{~min}\right)$, annealing $\left(58^{\circ} \mathrm{C}, 1 \mathrm{~min}\right)$ and extension ( $\left.72{ }^{\circ} \mathrm{C}, 8 \mathrm{~min}\right), 36$ cycles performed using a Mastercycler gradient machine (Eppendorf, Germany). The sizes of amplified products were determined by electrophoresis on $3 \%$ agarose gels.

\subsection{Statistical Analysis}

Statistical analysis was conducted with the R statistical platform (http://cran.r-project.org) using the package SNPassoc (SNPs-based whole-genome association studies. R package version 1.9-2. https://CRAN.R-project.org/package=SNPassoc). In the analysis of single SNPs, multiple inheritance models were used: Co-dominant, dominant, and recessive. Analysis of gene-gene interactions was carried out for the dominant and recessive models. Inheritance models were created with respect to minor alleles. The significance of interactions was calculated by comparing two models with and without the interaction term, using likelihood ratio tests. $p<0.05$ was considered statistically significant.

\section{Results}

Demographic characteristics of the IS and control groups, risk factors and TOAST classifications in stroke cases are shown in Table 1. All characteristics did not differ between the two groups except for age $(66.9 \pm 12.1$ vs. $56.8 \pm 9.8, p<0.0001)$ and the frequencies of diabetes mellitus $(27 \%$ vs. $13 \%$, $p=0.004)$ and dyslipidemia $(16 \% / 84 \%$ vs. $76 \% / 24 \%, p<0.0001)$. 
Table 1. Demographic and risk factors of stroke characteristics.

\begin{tabular}{cccc}
\hline Characteristic & Cases $(\boldsymbol{n}=\mathbf{1 4 7})$ & Control $(\boldsymbol{n = 1 1 7})$ & $p$ \\
\hline Age (years) & $66.9 \pm 12.1$ & $56.8 \pm 9.8$ & $<0.0001$ \\
BMI $\left(\mathrm{kg} / \mathrm{m}^{2}\right)$ & $27.6 \pm 4.8$ & $26.9 \pm 4.2$ & 0.286 \\
Sex (Males) & $54 \%(80)$ & $56 \%(65)$ & 0.854 \\
Smoking & $32 \%(47)$ & $24 \%(28)$ & 0.150 \\
Diabetes mellitus & $27 \%(40)$ & $13 \%(15)$ & 0.004 \\
Hypertension & $60 \%(88)$ & $51 \%(60)$ & 0.163 \\
Dyslipidemia & $16 \%(23)$ & $76 \%(89)$ & $<0.0001$ \\
\hline TOAST & & & \\
Large-vessel atherosclerosis & $46 \%(68)$ & & \\
Cardioembolism & $17 \%(25)$ & & \\
Small-vessel & $26 \%(38)$ & & \\
Others & $11 \%(16)$ & &
\end{tabular}

\subsection{Association between Overall IS and Genetic Variation in IL1B and IL1RN}

The genotype distributions were in Hardy-Weinberg equilibrium for IL1B (all individuals $p=0.081$, cases $p=0.741$, control group $p=0.073$ ) and IL1RN (all individuals $p=0.794$, cases $p=0.867$, control group $p=0.675)$. Observed genotype frequencies for the $I L-1 B: C(-31) \mathrm{T}$ polymorphism (rs1143627) were: $33.3 \% \mathrm{~T} / \mathrm{T}(n=88), 43.9 \% \mathrm{C} / \mathrm{T}(n=116), 22.7 \% \mathrm{C} / \mathrm{C}(n=60)$ and for alleles: $55.3 \% \mathrm{~T}$ and $44.7 \%$ C. The genotype frequencies for the IL1RN were 39.0\% $1 / 1(n=103), 46.2 \% 1 / 2(n=122), 14.8 \% 2 / 2$ $(n=39)$ and for alleles: $62.1 \% 1$ and $37.9 \% 2$. The IL1RN alleles 3 and 4 were rare and their frequencies did not significantly differ between the IS patients and the control group (1.9\% vs. $1.6 \%, p=0.765$ for allele 3 and $0.3 \%$ vs. $1.2 \%, p=0.122$ for allele 4 ). Baseline characteristics of the study group are shown in Table 1. The results of tests of association of the IL1RN and IL1B polymorphisms with stroke are summarized in Tables 2 and 3.

Table 2. An association of the IL1RN polymorphism with stroke under codominant, dominant, and recessive model.

\begin{tabular}{ccccccccc}
\hline Model & Control $(\boldsymbol{n}=\mathbf{1 1 7})$ & $\mathbf{\%}$ & Cases $(\boldsymbol{n = 1 4 7 )}$ & $\mathbf{\%}$ & OR & $\mathbf{9 5 \%}$ CI & $p$ \\
\hline Codominant & & & & & & & & \\
\hline $1 / 1$ & 54 & 46.2 & 49 & 33.3 & 1.00 & & & \\
$1 / 2$ & 49 & 41.9 & 73 & 49.7 & 1.64 & 0.97 & 2.79 & $0.647 *$ \\
$2 / 2$ & 14 & 12.0 & 25 & 17.0 & 1.97 & 0.92 & 4.21 & \\
\hline Dominant & & & & & & & & \\
\hline $1 / 1$ & 54 & 46.2 & 49 & 33.3 & 1.00 & & & \multirow{2}{*}{$0.358 *$} \\
$1 / 2-2 / 2$ & 63 & 53.8 & 98 & 66.7 & 1.71 & 1.04 & 2.83 & \\
\hline Recessive & & & & & & & & \\
\hline $1 / 1-1 / 2$ & 103 & 88.0 & 122 & 83.0 & 1.00 & & & \multirow{2}{*}{$0.650 *$} \\
$2 / 2$ & 14 & 12.0 & 25 & 17.0 & 1.51 & 0.75 & 3.05 & \\
\hline
\end{tabular}

* Adjusted by: age, diabetes mellitus, dyslipidemia.

The results of tests for association of the IL1RN and IL1B polymorphisms with stroke are summarized in Tables 2 and 3. In multivariable modeling, including covariates (age, diabetes mellitus, dyslipidemia), the association of the ILRN with stroke was insignificant (Table 2). For the IL1B polymorphism, the association under codominant and recessive models was insignificant after adjustment for covariates (age, diabetes mellitus, dyslipidemia), however with the dominant model, the risk of stroke with CT-CC was 2.3 higher than for TT homozygotes $(2.30(1.36-3.87) ; p=0.020)$ (Table 3). 
Table 3. An association of the $I L-1 B$ polymorphism with stroke under codominant, dominant, and recessive model.

\begin{tabular}{|c|c|c|c|c|c|c|c|c|}
\hline Model & Control $(n=117)$ & $\%$ & Cases $(n=147)$ & $\%$ & OR & \multicolumn{2}{|c|}{$95 \%$ CI } & $p^{*}$ \\
\hline $\mathrm{T} / \mathrm{T}$ & 51 & 43.6 & 37 & 25.2 & 1.00 & & & \multirow{3}{*}{0.065 * } \\
\hline $\mathrm{C} / \mathrm{T}$ & 45 & 38.5 & 71 & 48.3 & 2.17 & 1.24 & 3.82 & \\
\hline $\mathrm{C} / \mathrm{C}$ & 21 & 17.9 & 39 & 26.5 & 2.56 & 1.30 & 5.05 & \\
\hline \multicolumn{9}{|l|}{ Dominant } \\
\hline $\mathrm{T} / \mathrm{T}$ & 51 & 43.6 & 37 & 25.2 & 1.00 & & & \multirow{2}{*}{0.020 * } \\
\hline $\mathrm{C} / \mathrm{T}-\mathrm{C} / \mathrm{C}$ & 66 & 56.4 & 110 & 74.8 & 2.30 & 1.36 & 3.87 & \\
\hline \multicolumn{9}{|l|}{ Recessive } \\
\hline $\mathrm{T} / \mathrm{T}-\mathrm{C} / \mathrm{T}$ & 96 & 82.1 & 108 & 73.5 & 1.00 & & & \multirow{2}{*}{0.322 * } \\
\hline $\mathrm{C} / \mathrm{C}$ & 21 & 17.9 & 39 & 26.5 & 1.65 & 0.91 & 3.00 & \\
\hline
\end{tabular}

* Adjusted by: Age, diabetes mellitus, dyslipidemia.

In addition to single-locus analyses, we investigated whether the two genes interacted with respect to the modification of stroke risk (Figures 1 and 2). The analysis was conducted with the assumption of dominant or recessive models for each polymorphism and no evidence was found of gene-gene interaction with respect to IS risk. Although the raw $p$ value for the dominant $\mathrm{x}$ dominant model was 0.046, it turned out to be non-significant after adjustment for covariates.

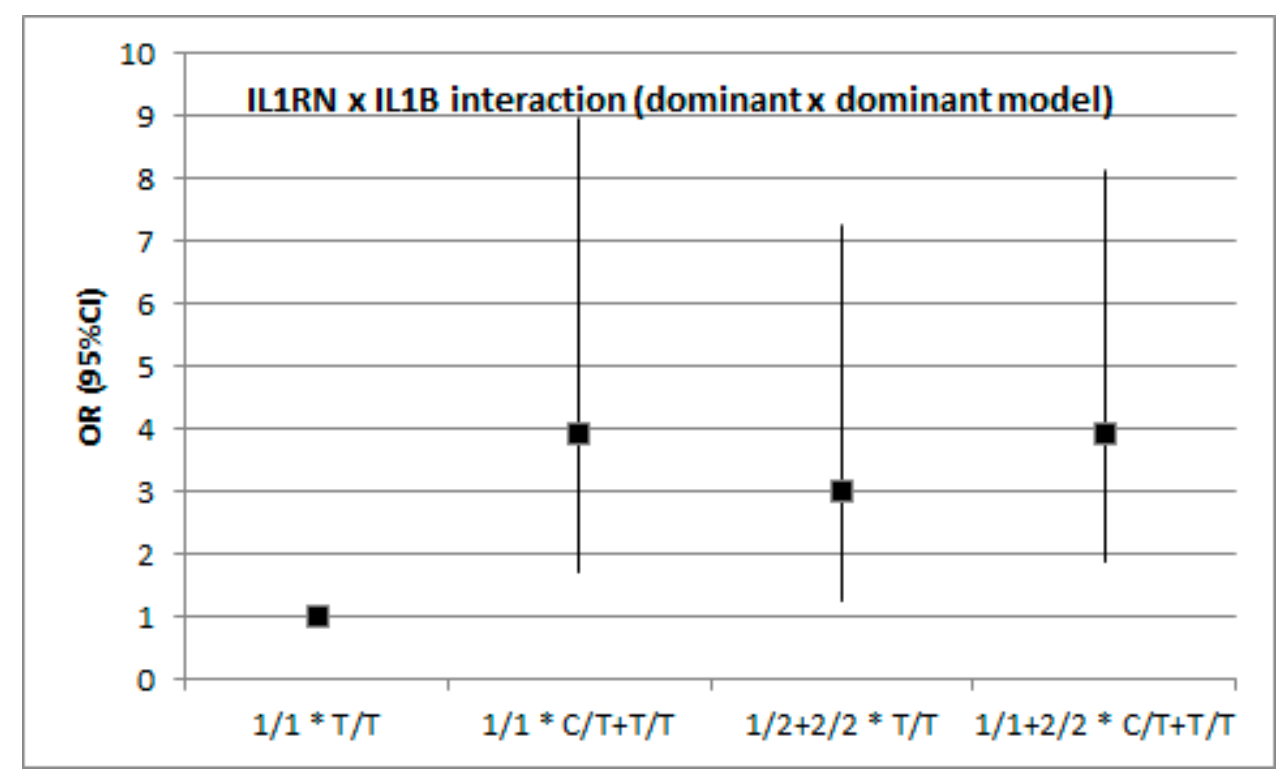

Figure 1. $I L 1 R N \times I L 1 B$ interaction (dominant $\times$ dominant model). Raw $p=0.046$, adjusted $p=0.232$ (age, diabetes mellitus, dyslipidemia status). 


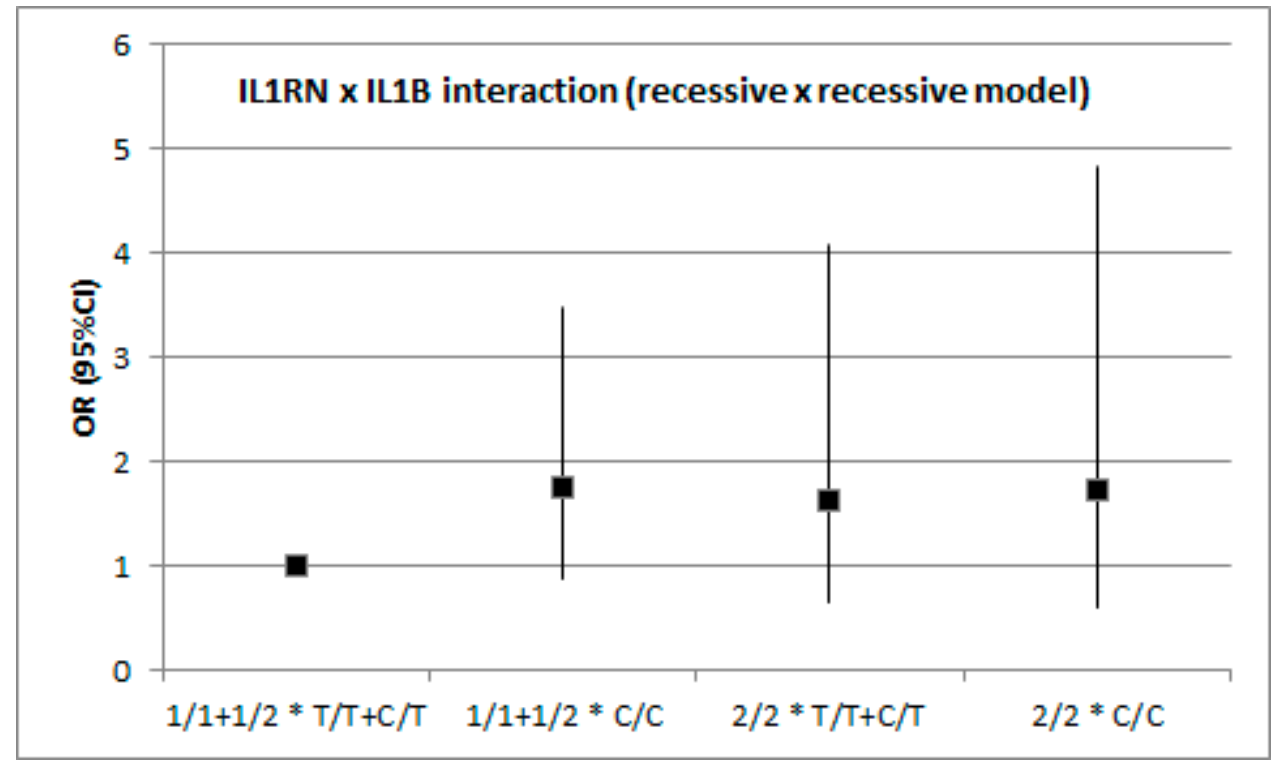

Figure 2. $I L 1 R N \times I L 1 B$ interaction (recessive $\times$ recessive model). Raw $p=0.502$, adjusted $p=0.910$ (age, diabetes mellitus, dyslipidemia status).

\subsection{Association between IS and Genetic Variation in IL1B and IL1RN by Stroke Subtype (TOAST)}

Each stroke subtype, i.e., CEI, SVI, LVI of the TOAST classification, was compared with control subjects (Tables 4 and 5). No significant associations were found between IL1RN and stroke under codominant, dominant, and recessive models by stroke subtype according to TOAST classification (Table 4). For the IL1B gene, the carriers of the C allele were significantly overrepresented in LVI subtypes compared with controls with $(1.99(1.05-3.79), p=0.036)$ (Table 5). For the other subtypes, we did not find any significant correlations (Table 5). 
Table 4. An association of the IL1RN polymorphism with stroke under codominant, dominant, and recessive models by stroke subtype (TOAST classification).

\begin{tabular}{|c|c|c|c|c|c|c|c|c|c|c|}
\hline Model & Control $(n=117)$ & CEI $(n=25)$ & OR $(95 \%$ CI) & $p^{*}$ & SVI $(n=38)$ & OR $(95 \%$ CI) & $p^{*}$ & LVI $(n=68)$ & OR $(95 \%$ CI) & $p^{*}$ \\
\hline \multicolumn{11}{|c|}{ Codominant } \\
\hline $1 / 1$ & $54(46.2)$ & $6(24.0)$ & 1.00 & & $13(34.2)$ & 1.00 & & $25(36.8)$ & 1.00 & \\
\hline $1 / 2$ & 49 (41.9) & $14(56.0)$ & $2.57(0.92-7.21)$ & & $19(50.0)$ & $1.61(0.72-3.60)$ & & $34(50.0)$ & $1.50(0.79-2.86)$ & \\
\hline $2 / 2$ & $14(12.0)$ & $5(20.0)$ & $3.21(0.85-12.09)$ & 0.388 & $6(15.8)$ & $1.78(0.57-5.52)$ & 0.947 & $9(13.2)$ & $1.39(0.53-3.63)$ & 0.974 \\
\hline \multicolumn{11}{|l|}{ Dominant } \\
\hline $1 / 1$ & $54(46.2)$ & $6(24.0)$ & 1.00 & & $13(34.2)$ & 1.00 & & $25(36.8)$ & 1.00 & \\
\hline $1 / 2-2 / 2$ & $63(53.8)$ & $19(76.0)$ & $2.71(1.01-7.28)$ & 0.261 & $25(65.8)$ & $1.65(0.77-3.53)$ & 0.854 & $43(63.2)$ & $1.47(0.80-2.72)$ & 0.982 \\
\hline \multicolumn{11}{|l|}{ Recessive } \\
\hline $1 / 1-1 / 2$ & $103(88.0)$ & $20(80.0)$ & 1.00 & & $32(84.2)$ & 1.00 & & $59(86.8)$ & 1.00 & \\
\hline $2 / 2$ & $14(12.0)$ & $5(20.0)$ & $1.84(0.60-5.68)$ & 0.695 & $6(15.8)$ & $1.38(0.49-3.88)$ & 0.752 & $9(13.2)$ & $1.12(0.46-2.75)$ & 0.823 \\
\hline
\end{tabular}

* Adjusted by: Age, diabetes mellitus, dyslipidemia.

Table 5. An association of the IL1B polymorphism with stroke under codominant, dominant, and recessive models by stroke subtype (TOAST classification).

\begin{tabular}{|c|c|c|c|c|c|c|c|c|c|c|}
\hline Model & Control $(n=117)$ & CEI $(n=25)$ & OR $(95 \%$ CI) & $p^{*}$ & SVI $(n=38)$ & OR $(95 \%$ CI) & $p^{*}$ & LVI $(n=68)$ & OR $(95 \%$ CI) & $p^{*}$ \\
\hline \multicolumn{11}{|c|}{ Codominant } \\
\hline $\mathrm{T} / \mathrm{T}$ & $51(43.6)$ & $5(20.0)$ & 1.00 & & $8(21.1)$ & 1.00 & & 19 (27.9) & 1.00 & \\
\hline $\mathrm{C} / \mathrm{T}$ & 45 (38.5) & $14(56.0)$ & $3.17(1.06-9.50)$ & & $19(50.0)$ & $2.69(1.07-6.74)$ & & $33(48.5)$ & $1.97(0.99-3.93)$ & \\
\hline $\mathrm{C} / \mathrm{C}$ & $21(17.9)$ & $6(24.0)$ & $2.91(0.80-10.60)$ & 0.074 & $11(28.9)$ & $3.34(1.18-9.48)$ & 0.236 & $16(23.5)$ & $2.05(0.89-4.72)$ & 0.069 \\
\hline \multicolumn{11}{|l|}{ Dominant } \\
\hline $\mathrm{T} / \mathrm{T}$ & $51(43.6)$ & $5(20.0)$ & 1.00 & & $8(21.1)$ & 1.00 & & $19(27.9)$ & 1.00 & \\
\hline $\mathrm{C} / \mathrm{T}-\mathrm{C} / \mathrm{C}$ & $66(56.4)$ & $20(80.0)$ & $3.09(1.09-8.80)$ & 0.305 & $30(78.9)$ & $2.90(1.22-6.86)$ & 0.106 & $49(72.1)$ & $1.99(1.05-3.79)$ & 0.036 \\
\hline \multicolumn{11}{|l|}{ Recessive } \\
\hline $\mathrm{T} / \mathrm{T}-\mathrm{C} / \mathrm{T}$ & $96(82.1)$ & $19(76.0)$ & 1.00 & & $27(71.1)$ & 1.00 & & $52(76.5)$ & 1.00 & \\
\hline $\mathrm{C} / \mathrm{C}$ & $21(17.9)$ & $6(24.0)$ & $1.44(0.51-4.05)$ & 0.225 & $11(28.9)$ & $1.86(0.80-4.34)$ & 0.874 & $16(23.5)$ & $1.41(0.68-2.93)$ & 0.993 \\
\hline
\end{tabular}

* Adjusted by: Age, diabetes mellitus, dyslipidemia. 


\section{Discussion}

Ischemic stroke is a disease of complex etiology, and it is generally accepted that both environmental and genetic factors play a crucial role in the development of the disease. Although there are many studies which have indicated that inflammatory cytokines and their genetic polymorphisms play an important role in the pathogenesis of IS, the results are still controversial. In this study, two important polymorphisms of the IL1 cluster were investigated for their association with stroke. We have not shown any connection between genetic variants of ILRN VNTR with overall stroke or subtypes. This is in line with previous studies on IS [20]. In contrast some studies, have reported an association of the IL1RN with stroke [21]. This inconsistency could be explained with the rather relatively small size of study groups than differences between populations. However, we have shown that the IL1B:T(-31)C polymorphism is independently associated with overall IS and subtype of IS in the homogeneous Polish population.

For the IL1B:C(-31)T polymorphism, we found that carriers of the $C$ allele were associated with a higher risk of overall stroke. Moreover, we found that CT/CC genotypes can increase the risk of subtypes of IS. The relationship of IL1B polymorphism and stroke has been examined in several previous studies and our results remain in line with those presented so far. Extensive studies on the IL1B polymorphism at position -511 have indicated that IL1B:-511T carriers had higher levels of IL1B than IL1B:-511C and were associated with increased risk of IS [22]. It is also worth mentioning the study by Iacoviello et al. [23] which is the main source of research heterogeneity because this study reported that TT homozygotes of IL1B:-511 are associated with a decreased risk of IS. However, patients in this study were relatively young. Thus, the association between IL1B polymorphism and IL1B production still remains controversial. A recent study has documented that IL1B mRNA was increased in the TT genotype [24] whereas Hall et al. [25] showed a 2-3-fold increase in IL1B protein secretion in subjects with the $\mathrm{T}$ allele at -511 and the $\mathrm{C}$ allele at -31 .

We found no interaction between IL1RN and IL1B concerning IS risk assuming the dominant $x$ dominant and recessive $x$ recessive models. The gene-gene interaction was analyzed using a linear model in which only two (and the same) inheritance patterns for each locus were considered. This approach could possibly have less power as compared with a non-parametric and model-free multifactor dimensionality reduction method that has been shown to have reasonable power to detect epistasis [26].

The polymorphism of IL1B at -31 is tightly linked with the polymorphism at -511 . However, it is unclear whether the $C$ or $T$ allele of IL1B -31 is associated with high expression. We have not measured the plasma IL1B and IL1RA levels and this can be considered as a limitation of our study. It is worth emphasizing that genetic variations of IL1B -31 and von Willebrand factor are associated with the recanalization rate of fibrinolysis with tissue-type plasminogen activator, and thus with treatment efficacy [27]. As the authors report, the mechanisms by which these SNPs modulate recanalization could be related to homeostasis modulation by modification of coagulation factor activities. Manso et al. [28] also tested the inflammatory genes IL1B, interleukin 6 (IL6), myeloperoxidase (MPO), and TNF with stroke susceptibility, and demonstrated that only two SNPs of IL6 and one MPO single-nucleotide polymorphism were significantly associated with stroke risk in their sample. Probably, an observed lesser genetic influence is related to widespread classical risk factors, or lifestyle. Some studies have reported that IL1B:C(-31)T and IL1RN:VNTR polymorphisms are significantly correlated with the development of CAD, and thus atherosclerosis process [3,29]. However, other studies conducted in different populations have not confirmed this and these associations still remain controversial. In our previous study we showed no association between polymorphisms of IL1B:C(-31)T/IL1RN (VNTR) or their haplotypes and CAD in the Polish population [30], which may suggest lesser importance of genetic factors in the development of atherosclerotic diseases in our population.

Nevertheless, IL1B is a potent pro-inflammatory cytokine and plays a major role in the development of both inflammation processes and thrombosis. It is hypothesized that in IS development, IL1B is involved in thrombus formation rather than in atherosclerosis progression because IL1 
induces tissue factor and plasminogen activator inhibitor type 1 gene expression [31]. However, this cytokine can induce complex biological effects by the regulation of gene expression of multiple cell types [32]. Therefore, more mechanisms should be considered in the development of IS, although both inflammatory and prothrombotic mechanisms seem to play a fundamental role. The formation of a thrombus leading to occlusion of a vessel is the endpoint which is influenced by many factors (genes, hypertension, hyperlipidemia, diabetes mellitus, etc.), and the gene-environment interaction can be of great importance. Thus, the ILIB C allele may not be associated directly with IS per se, but could be modulating cytokines in the inflammatory processes that affect the development of atherosclerosis resulting in IS. It has been shown that genetic variants of $I L 1 B$ that predict higher inflammatory phenotypes modify the risk of $\mathrm{Lp}(\mathrm{a})$ in mediating long-term cardiovascular events [33]. These results indicate that $I L 1 B$ can modify many pathways involved in the development of atherosclerosis and thus, cardiovascular events. Additionally, some studies have also reported that the risk of stroke increases with the number of high-risk genotypes in proinflammatory gene polymorphisms carried by an individual, thus suggesting that such polymorphisms may act synergistically [34]. We have evaluated genetic variants of only two genes which are crucial in inflammation. IS is a very complicated and extremely complex disease and its pathomechanism is still not fully explained. It is not yet known how many risk factors in the development of atherosclerosis could be modulated by the genetic variants of $I L 1 B$, which acts as a key regulator in inflammatory processes.

In different populations with varying intensity of classical risk factors, the impact of genetics may be found to have a variable extent. Previous studies have reported that ethnicity or regional locations are very important in the determination of environmental risk factors [35]. One of advantages of the present study is that it included a well-characterized and homogeneous patients' group (from the northwest region of Poland), but it should be emphasized that our society has strongly expressed classical risk factors for IS. It should be noted that observed differences between the study group and the controls could interfere with the assessment of the role for the ILIRN polymorphism in the development of IS. Diabetes, which is a widely recognized risk factor for the development of atherosclerosis, has been more frequent in IS patients, while dyslipidemia has been less frequent. However, the IS patients had been already treated (b-blocker, statin, etc.) which could have downregulated to some extent the inflammatory process agents, while the control group comprised subjects without treatment for this. Moreover, the control group was slightly younger than the IS group, which may have had some impact on the obtained results, and could be considered another limitation of our study. The population included in the study was homogeneous (monoethnic, Polish) and, therefore, our data need to be confirmed in different ethnic groups.

\section{Conclusions}

The complex interplay between genetic backgrounds, clinical and lifestyle factors, and the environment may ultimately lead to the development of stroke. In the present study, we present supporting evidence for a role of the IL1B inflammatory gene in stroke susceptibility. Our findings confirm previous genetic observations, highlighting the need for further functional studies, particularly in view of the possible utility of $I L 1 B$ as a diagnostic biomarker for stroke.

Author Contributions: Conceptualization, I.G. and L.C.; data curation, M.K. and B.K.; formal analysis, L.C.; funding acquisition, A.C.; investigation, K.L. and O.B.; methodology, K.L. and P.J.; project administration, A.C. and A.B.; resources, P.J. and O.B.; software, M.K. and A.B.; supervision, I.G. and A.C.; validation, M.K.; visualization, M.K. and B.K.; writing—original draft, I.G.; writing—review \& editing, I.G. and L.C.

Funding: The study was financed by the internal funding of Pomeranian Medical University, Szczecin, Poland.

Conflicts of Interest: The authors declare no conflict of interest. 


\section{References}

1. Bochner, B.S.; Luscinskas, F.W.; Gimbrone, M.A., Jr.; Newman, W.; Sterbinsky, S.A.; Derse-Anthony, C.P.; Klunk, D.; Schleimer, R.P. Adhesion of human basophils, eosinophils, and neutrophils to interleukin-1 activated endothelial cells: Contributions of endothelial adhesion molecules. J. Exp. Med. 1991, 173, 1553-1557. [CrossRef] [PubMed]

2. Dinarello, C.A. Biologic basis for interleukin-1 in disease. Blood 1996, 87, 2095-2147. [PubMed]

3. Marculescu, R.; Endler, G.; Schillinger, M.; Iordanova, N.; Exner, M.; Hayden, E.; Huber, K.; Wagner, O.; Mannhalter, C. Interleukin-1 receptor antagonist genotype is associated with coronary atherosclerosis in patients with type 2 diabetes. Diabetes 2002, 51, 3582-3585. [CrossRef] [PubMed]

4. Rios, D.L.; Cerqueira, C.C.; Bonfim-Silva, R.; Araújo, L.J.; Pereira, J.F.; Gadelha, S.R.; Barbosa, A.A. Interleukin-1 beta and interleukin-6 polymorphism associations with angiographically assessed coronary artery disease in Brazilians. Cytokine 2010, 50, 292-296. [CrossRef] [PubMed]

5. Zhang, Y.M.; Zhong, L.J.; He, B.X.; Li, W.C.; Nie, J.; Wang, X.; Chen, X.T. The correlation between polymorphism at position- $511 \mathrm{C} / \mathrm{T}$ in the promoter region of interleukin $1 \mathrm{~B}$ and the severity of coronary heart disease. Zhonhua Yi Xue Yi Chuan Xue Za Zhi 2006, 3, 86-88.

6. Santilla, S.; Savinainen, K.; Hurme, M. Presence of the IL-1RA allele2(IL1RN*2) is associated with enhanced IL-1beta production in vitro. Scan. J. Immunol. 1998, 47, 195-198. [CrossRef]

7. Blakemore, A.I.; Tarlow, J.K.; Cork, M.J.; Gordon, C.; Emery, P.; Duff, G.W. Interleukin-1 receptor antagonist gene polymorphism as a disease severity factor in systemic lupus erythematosus. Artritis Rheum. 1994, 37, 1380-1385. [CrossRef] [PubMed]

8. Davies, C.A.; Loddick, S.A.; Toulmond, S.; Stroemer, R.P.; Hunt, J.; Rothwell, N.J. The progression and topographic distribution of interleukin-1beta expression after permanent middle cerebral artery occlusion in the rat. J. Cereb. Blood Flow Metab. 1999, 19, 87-98. [CrossRef]

9. Touzani, O.; Boutin, H.; Chuquet, J.; Rothwell, N. Potential mechanisms of interleukin-1 involvement in cerebral ischaemia. J. Neuroimmunol. 1999, 100, 203-215. [CrossRef]

10. Touzani, O.; Boutin, H.; LeFeuvre, R.; Parker, L.; Miller, A.; Luheshi, G.; Rothwell, N. Interleukin-1 influences ischemic brain damage in the mouse independently of the interleukin-1 receptor. J. Neurosc. 2002, 22, 38-43. [CrossRef]

11. Tarlow, J.K.; Blakemore, A.I.; Lennard, A.; Solari, R.; Hughes, H.N.; Steinkasserer, A.; Duff, G.W. Polymorphism in human IL-1 receptor antagonist gene intron 2 is caused by variable numbers of an 86-bp tandem repeat. Hum. Genet. 1993, 91, 403-404. [CrossRef] [PubMed]

12. Hurme, M.; Santila, S. IL-1 receptor antagonist (IL-Ra) plasma levels are co-ordinately regulated by both IL-Ra and IL-1beta genes. Eur. J. Immunol. 1998, 47, 195-198.

13. Worrall, B.B.; Azhar, S.; Nyquist, P.A.; Ackerman, R.H.; Hamm, T.L.; DeGraba, T.J. Interleukin-1 receptor antagonist gene polymorphisms in carotid atherosclerosis. Stroke 2003, 34, 790-793. [CrossRef] [PubMed]

14. Fragoso, J.M.; Delgadillo, H.; Llorente, L.; Chuquiure, E.; Juárez-Cedillo, T.; Vallejo, M.; Lima, G.; Furuzawa-Carballeda, J.; Peña-Duque, M.A.; Martínez-Ríos, M.A.; et al. Interleukin 1 receptor antagonist polymorphisms are associated with the risk of developing acute coronary syndrome in Mexicans. Immunol. Lett. 2010, 133, 106-111. [CrossRef] [PubMed]

15. Francis, S.E.; Camp, N.J.; Dewberry, R.M.; Gunn, J.; Syrris, P.; Carter, N.D.; Jeffery, S.; Kaski, J.C.; Cumberland, D.C.; Duff, G.W.; et al. Interleukin-1 receptor antagonist gene polymorphism and coronary artery disease. Circulation 1999, 99, 861-866. [CrossRef] [PubMed]

16. Olofsson, P.S.; Sheikine, Y.; Jatta, K.; Ghaderi, M.; Samnegård, A.; Eriksson, P.; Sirsjö, A. A functional interleukin-1 receptor antagonist polymorphism influences atherosclerosis development. The interleukin-1 beta: Interleukin-1 receptor antagonist balance in atherosclerosis. Circ. J. 2009, 73, 1531-1536. [CrossRef] [PubMed]

17. Yan, W.; Chen, Z.Y.; Chen, J.Q.; Chen, H.M. Association between the interleukin-1B gene-511C/T polymorphism and ischemic stroke: An update meta-analysis. Genet. Mol. Res. 2016, 15. [CrossRef]

18. Li, N.; He, Z.; Xu, J.; Liu, F.; Deng, S.; Zhang, H. Association of PDE4D and IL-1 gene polymorphism with ischemic stroke in a Han Chinese population. Brain Res. Bull. 2010, 81, 38-42. [CrossRef] 
19. Adams, H.P., Jr.; Bendixen, B.H.; Kappelle, L.J.; Biller, J.; Love, B.B.; Gordon, D.L.; Marsh, E.E., 3rd. Classification of subtype of acute ischemic stroke: Definitions for use in a multicenter clinical trial. Stroke 1993, 24, 35-41. [CrossRef]

20. Yang, Y.; Wu, W.; Wang, L.; Ding, Y. Lack of association between interleukin-1 $\beta$ receptor antagonist gene 86-bp VNTR polymorphism and ischemic stroke: A meta-analysis. Medicine 2018, 97, e11750. [CrossRef]

21. Noha, A.R.; Hanan, S.M. Influence of interleukin-1 gene cluster polymorphism on the susceptibility and outcomes of acute stroke in Egyptian patients. Cell Biochem. Biophys. 2015, 71, 637-647.

22. Nemetz, A.; Nosti-Escanilla, M.P.; Molnár, T.; Köpe, A.; Kovács, A.; Fehér, J.; Tulassay, Z.; Nagy, F.; García-González, M.A.; Peña, A.S. IL-1B gene polymorphism influence the course and severity of inflammatory bowel disease. Immunogenetics 1999, 49, 527-531. [CrossRef] [PubMed]

23. Iacoviello, L.; Di Castelnuovo, A.; Gattone, M.; Pezzini, A.; Assanelli, D.; Lorenzet, R.; Del Zotto, E.; Colombo, M.; Napoleone, E.; Amore, C.; et al. Polymorphisms of the interleukin-1beta gene affect the risk of myocardial infarction and ischemic stroke at young age and the response of mononuclear cells to stimulation in vitro. Arterioscler. Thromb. Vasc. Biol. 2005, 25, 222-227. [CrossRef] [PubMed]

24. Kimura, R.; Nishioka, T.; Soemantri, A.; Ishida, T. Cis-acting effect of the IL-1B C-31T polymorphism on IL-1beta mRNA expression. Genes Immun. 2005, 5, 571-575.

25. Hall, S.K.; Perregaux, D.G.; Gabel, C.A.; Woodworth, T.; Durham, L.K.; Huizinga, T.W.; Breedveld, F.C.; Seymour, A.B. Correction of polymorphic variation in the promoter region of the interleukin- $1 \beta$ gene with secretion of interleukin $1 \beta$ protein. Arthritis Reum. 2004, 50, 1976-1983. [CrossRef] [PubMed]

26. Wei, L.K.; Menon, S.; Griffiths, L.R.; Gan, S.H. Signaling pathway genes for blood pressure, folate and cholesterol levels among hypertensives: An epistasis analysis. J. Hum. Hypertens. 2015, 29, 99-104. [CrossRef] [PubMed]

27. Fernández-Cadenas, I.; Del Río-Espínola, A.; Giralt, D.; Domingues-Montanari, S.; Quiroga, A.; Mendióroz, M.; Ruíz, A.; Ribó, M.; Serena, J.; Obach, V.; et al. IL1B and VWF variants are associated with fibrynolitic early recanalization in patients with ischemic stroke. Stroke 2012, 43, 2659-2665. [CrossRef] [PubMed]

28. Manso, H.; Krug, T.; Sobral, J.; Albergaria, I.; Gaspar, G.; Ferro, J.M.; Oliveira, S.A.; Vicente, A.M. Variants in the inflammatory IL6 and MPO genes modulate stroke susceptibility through main effects and gene-gene interactions. J. Cereb. Blood Flow Metab. 2011, 31, 1751-1759. [CrossRef] [PubMed]

29. Rechciński, T.; Grebowska, A.; Kurpesa, M.; Sztybrych, M.; Peruga, J.Z.; Trzos, E.; Rudnicka, W.; Krzemińska-Pakuła, M.; Chmiela, M. Interleukin-1b and interleukin-1 receptor inhibitor gene cluster polymorphisms in patients with coronary artery disease after percutaneous angioplasty or coronary artery bypass grafting. Kardiol. Pol. 2009, 67, 601-610.

30. Goracy, J.; Goracy, I.; Safranow, K.; Taryma, O.; Adler, G.; Ciechanowicz, A. Lack of association of interleukin-1 gene cluster polymorphisms with angiographically documented coronary artery disease: Demonstration of association with hypertension in the Polish population. Arch. Med. Res. 2011, 42, 426-432. [CrossRef] [PubMed]

31. Larsson, P.; Ulfhammer, E.; Karlsson, L.; Bokarewa, M.; Wåhlander, K.; Jern, S. Effects of IL-1beta and IL-6 on tissue-type plasminogen activator expression in vascular endothelial cells. Thromb. Res. 2008, 123, 342-351. [CrossRef] [PubMed]

32. Lynch, M.A. Neuroinflammatory changes negatively impact on LTP: A focus on IL-1beta. Brain Res. 2015, 1621, 197-204. [CrossRef] [PubMed]

33. Naka, K.K.; Bechlioullis, A.; Marini, A.; Sionis, D.; Vakalis, K.; Triantis, G.; Wilkins, L.; Rogus, J.; Kornman, K.S.; Witztum, J.L.; et al. Interleukin-1 genotypes modulate the long-term effect of lipoprotein (a) on cardiovascular events: The Ioannina study. J. Clin. Lipidol. 2018, 12, 338-347. [CrossRef] [PubMed]

34. Flex, A.; Gaetani, E.; Papaleo, P.; Straface, G.; Proia, A.S.; Pecorini, G.; Tondi, P.; Pola, P.; Pola, R. Proinflammatory genetic profiles in subjects with history of ischemic stroke. Stroke 2004, 35, 2270-2275. [CrossRef] [PubMed]

35. Koukkou, E.; Watts, G.F.; Mazurkiewicz, J.; Lowy, C. Ethnic differences in lipid and lipoprotein metabolism in pregnant women of African and Caucasian origin. J. Clin. Pathol. 1994, 47, 1105-1107. [CrossRef] [PubMed]

(C) 2019 by the authors. Licensee MDPI, Basel, Switzerland. This article is an open access article distributed under the terms and conditions of the Creative Commons Attribution (CC BY) license (http://creativecommons.org/licenses/by/4.0/). 